\title{
0 corpo como espaço de aprendizagem: reflexões a partir das vivências de um grupo de teatro formado por adultos na maturidade
}

Evany Bettine de Almeida* , Anna Karenina Azevedo-Martins*, Viviane Abreu Nunes*

\section{Resumo}

Partindo de reflexões sobre o lugar do corpo na sociedade, neste artigo é apresentado um estudo investigativo e descritivo sobre a relação entre a educação do corpo e a experiência teatral de 15 adultos na maturidade, entre setembro e dezembro de 2010. Avaliamos a influência de atividades que evidenciam o corpo em diferentes aspectos da vida desses indivíduos, utilizando* Escola de Artes, Ciências e Humanidades (EACH), Universidade de São Paulo (USP), São Paulo, SP, Brasil. eva.bettine@gmail.com, karenina@usp.br, vanunes@ib.usp.br -se o método etnográfico da observação participante e a técnica qualitativa grupo focal. Foram entrevistadas 13 mulheres e 2 homens, cujas idades variaram entre 60 e 85 anos. A maioria concluiu o ensino superior (65\%); os demais se dividiram entre ensino médio e primário. Para analisar os depoimentos, optamos pela construção do discurso do sujeito coletivo e verificamos que essas atividades, que valorizam a expressão corporal, contribuem para o exercício da criatividade, estimulam o trabalho cooperativo, permitem a ampliação da rede de suporte social e favorecem a aprendizagem no seu sentido amplo.

\section{Palavras-chave}

Aprendizagem; corpo; educação. 


\title{
The body as place of learning: reflections from the experiences of a drama group formed by mature adults
}

\begin{abstract}
Based on the discussion about the position of the body within society, this work presents an exploratory study concerning the relationship between the education of the body and the experiences of a drama group formed by 15 mature adults, during the period from September to December, 2010. We investigated the influence of activities which highlight the body on different aspects of these individuals' life by using the ethnographic method for participative observation and the focus group qualitative technique. 13 women and 2 men, whose ages ranged between 60 and 85 years, were interviewed. Most of them had completed Higher Education (65\%), having the others completed high school and elementary school. The recorded statements were analyzed through the construction of the collective subject discourse and we could conclude that the activities which put the body in evidence contribute to creativity, encourage cooperative work, allow for the expansion of social network and favour the learning process in its broader sense.
\end{abstract}

Keywords

Body; education; learning process. 


\section{Introdução}

Uma questão que tem permeado a discussão sobre como entendemos o corpo no processo de ensino-aprendizagem é a compreensão de como somos e nos tornamos educados. Para atingir essa compreensão, devemos considerar que toda educação é a educação do corpo, e que esta percorre caminhos diversos, além de adotar práticas contraditórias, ditando, aplicando fórmulas e formas de contenção, tanto de necessidades fisiológicas quanto de desejos. Dessa forma, o corpo é educado pelas roupas, pela comida, pelas religiões, pela mídia, pela arquitetura (Zarankin, 2002), pelo tamanho dos cômodos, pelos móveis e objetos (Sant'Anna, 2000).

Segundo Foucault (1984), que nos convida a pensar sobre a educação do corpo, cada época elabora sua retórica corporal. Para ele, todas as marcas, formas e propostas para o funcionamento do corpo transformam-se com o tempo, substituem-se, assim como as representações se deslocam. Nesse sentido, Fraga (2001) afirma que o corpo é resultado provisório de diversas pedagogias que o conformam em determinadas épocas, lugares e culturas, ou seja, é construído histórica, cultural e socialmente, a partir de representações e por meio do outro, que precisa existir para que o sujeito possa se perceber.

Apesar de reconhecer que toda educação é educação do corpo, paradoxalmente, observamos maior valorização dos aspectos intelectuais quando se faz referência ao processo educativo formal, sendo o corpo visto apenas como elemento acessório, um espaço para a manifestação das capacidades mentais. A partir dessa constatação, verificamos a necessidade de fazer um resgate histórico das relações entre corpo e sociedade, a fim de melhor entender os processos que legitimaram o modelo contemporâneo da educação do corpo. Entre os elementos conceituais que contribuem para essa análise estão a lógica cartesiana para a hierarquização da mente sobre o corpo e suas consequências. Para Gaya (2006), essa visão dualista do sujeito, denominada dualismo mutilante, enunciada por René Descartes [15961650], continua vigente nas práticas pedagógicas atuais. E essa compreensão do corpo separado do sujeito que pensa pode fazer emergir a necessidade de evitar tudo o que contraria o ideal de perfeição do corpo, que pode ser tanto uma doença quanto a velhice. Nesse aspecto, Pinto (2004) afirma que os conceitos de juventude, beleza e felicidade estão profundamente ligados à necessidade de educar o corpo, adequando-o a padrões éticos e estéticos coerentes com o modelo social vigente (Sfez, 1995). Procuramos, dessa forma, imprimir ao corpo características, 
rótulos e marcas que o ligam a um sistema mercadológico e refletem essa ideia de pertencimento cultural.

Embora convivamos com a ideia do corpo separado da mente, alguns autores apontam formas de superação dessa dualidade. Nóbrega (2005) encontra essa possibilidade nas reflexões de Merleau-Ponty (1999) e Maturana e Varela (2001), que entendem a mente não como entidade desassociada, mas conectada a todo o corpo em uma relação de interdependência. Portanto, se o que se deseja é pensar no corpo e no processo de aprendizagem, é necessário começar estabelecendo novas relações entre esses dois temas. Pensar no corpo no processo educativo requer, portanto, que se reflita, primeiramente, sobre o conceito de aprendizagem e se tenha em mente que o corpo é, ao mesmo tempo, local de atuação do educador e do educando.

Segundo Piaget (1979), o processo de aprendizagem pode ser considerado como a forma pela qual os seres adquirem novos conhecimentos, desenvolvem competências e mudam o comportamento. Essa mudança de comportamento é possível quando se cria um espaço de convivência que permita experiências na relação com o outro e consigo mesmo. Para Ausubel (1982, apud Pelizzari, 2002), as pessoas aprendem quando são capazes de atribuir algum significado àquele conhecimento, quando o associam a outro e fazem ligações que começam a tomar sentido diferente, reforçando ou construindo um novo conhecimento, o que constitui a aprendizagem significativa. A ideia de aprendizagem significativa é retomada e complementada por Maroni (2008), que considera possível dar sentido ao conhecimento apenas quando o ser humano pensante participa de maneira integral do processo de aprendizagem, o que, segundo Dowbor (2008), requer a inclusão do corpo e de sua história nesse processo, de maneira mais consciente.

Ainda nesse sentido, Becker (1993) propõe um conceito de aprendizagem que se aproxima da concepção epistemológica de vários autores, dentre eles Paulo Freire e Vygotsky, que têm em comum a ação do sujeito colocada no cerne do processo de aprendizagem. É com base nessa prática centrada no sujeito que entendemos a relação indissociável entre corpo e aprendizado.

E como temos pensado o lugar do corpo na escola? A despeito de a Educação Infantil no Brasil ser caracterizada pela preparação da criança para a vida adulta, pelo ensino de regras sociais; embora seja recomendada a utilização do corpo como instrumental necessário para o desenvolvimento cognitivo (Brasil, 2001), à medida que se avança nas séries escolares, observamos gradativa perda de espaço curricular 
para o corpo em movimento na sala de aula e a legitimação desse em ambiente extraclasse. Isso não só reafirma a fragmentação corpo-mente, como explicita a ideia do corpo como elemento acessório no processo de aprendizagem. Não obstante, já não há como pensar em autonomia, sem que esta inclua a possibilidade de o indivíduo apoderar-se de seu próprio corpo, quer pela expressão, quer pelo autoconhecimento (Campos, 2006). Embora aqui façamos referência ao corpo e a sua educação circunscritos ao ambiente escolar, devemos considerar que as consequências da fragmentação corpo-mente se estendem a todas as fases da vida do indivíduo e influenciam não só a forma como aprendemos, mas também como entendemos as modificações nos nossos corpos ao longo do tempo.

\section{0 corpo que aprende é o corpo que envelhece}

Existe um conjunto de significados que cada sociedade atribui às mudanças que o tempo de vida vai imprimindo nos corpos e, portanto, na aparência dos indivíduos. Particularmente, em nossa cultura ocidental, cujo paradigma valoriza a juventude, o envelhecimento do corpo expõe fragilidades e causa estranheza ante a própria imagem no espelho (Goldfarb, 1998). Além disso, essas mudanças concorrem com eventos normativos, como o afastamento do mundo do trabalho, a redução do poder aquisitivo, a saída dos filhos de casa e, ainda, os possíveis eventos não normativos, como viuvez, perda de amigos e de pessoas ligadas por laços familiares. Segundo Baltes, Reese e Lipsitt (1980), o desenvolvimento de cada sujeito é o resultado da interação entre eventos normativos e não normativos; mas, para enfrentar essas questões, as pessoas precisam utilizar diversas estratégias; e as que surtem melhores efeitos perpassam pela busca de um novo significado para suas vidas.

Buscar essa ressignificação requer várias ações que visam aumentar a expectativa de uma vida com qualidade e que vão além dos cuidados com a saúde. Essas características remetem ao conceito de envelhecimento ativo, termo adotado pela Organização Mundial da Saúde para reconhecer que outros fatores afetam o modo como os indivíduos e as populações envelhecem (Kalache; Kickbush, 1997). Vale ressaltar, porém, que a palavra "ativo" se refere também à participação contínua nas questões sociais, econômicas, culturais, espirituais e civis; e não se relaciona somente à capacidade de estar fisicamente ativo ou de fazer parte da força de trabalho.

A partir da perspectiva do envelhecimento ativo, destaca-se a educação permanente, que significa aprender de forma constante, interativa e cumulativa, atendendo 
não apenas a uma necessidade de renovação cultural, mas, também, valorizando a autonomia dos indivíduos numa sociedade em rápida transformação (Palma; Cachioni, 2006). Isso se torna especialmente relevante em razão da crescente expansão do número de pessoas idosas em nossa sociedade (Camarano, 2006). Diante disso, cada vez mais se tem destacado a necessidade da criação de projetos que, por meio da educação permanente, estimulem as pessoas acima de 60 anos a serem mais autônomas, investindo-se na reinserção da população idosa, não necessariamente no mundo do trabalho, mas no convívio em um grupo fora do núcleo familiar. Nesse contexto, as atividades artísticas apresentam-se como estratégias facilitadoras do aprendizado que, no seu sentido amplo, compreende não só aquisição de conhecimentos e desenvolvimento de habilidades, mas, também, mudanças no comportamento (Piaget, 1979). Tais atividades figuram, portanto, como possibilidades de transformação pessoal mediando essa reinserção.

A relação entre atividades artísticas, aprendizado e reinserção social tem sido uma preocupação presente nas atividades desenvolvidas no Núcleo de Artes Cênicas da Estação Ciência da Universidade de São Paulo. Dessa forma, decidimos investigar, a partir da perspectiva do processo de ensino-aprendizagem, as vivências desse grupo de teatro formado por adultos na maturidade, denominado "Só com Experiência”. Esse nome não diz respeito a uma experiência teatral anterior; mas, sim, à experiência de vida, que é a bagagem necessária para a participação nas atividades propostas, que são pensadas para permitir e favorecer o desenvolvimento do indivíduo e do grupo.

Assim, a partir do diálogo entre educação, corpo e vivências desse grupo de teatro, pretendemos pensar qual o lugar do corpo no processo de aprendizagem que contempla diversos domínios da vida do indivíduo, como a ampliação da rede de suporte social; a aquisição de novos conhecimentos; a relação com o próprio corpo e com o corpo do outro; e o autocuidado, entendido como cuidado pessoal requerido pelo indivíduo para regular o seu funcionamento e desenvolvimento (Orem, 1985, apud Victor et al., 2010), por meio de atividades para melhorar a sua saúde e trazer-lhe bem-estar. Essa reflexão parece-nos extremamente pertinente diante das discussões contemporâneas sobre a construção da autonomia do indivíduo e o seu aprendizado.

\section{Material, métodos e procedimentos}

Participaram deste estudo 15 alunos do curso de teatro do Núcleo de Artes Cênicas da Estação Ciência, com idades entre 60 e 85 anos. A pesquisa seguiu as normas 
estabelecidas na Resolução 196/96 do Conselho Nacional de Saúde (BRASIL, 1998) que orienta as pesquisas envolvendo seres humanos. 0 estudo foi desenvolvido nas dependências da Estação Ciência, um centro pertencente à Pró-Reitoria de Cultura e Extensão da Universidade de São Paulo, cujo objetivo é a popularização da ciência e a promoção da educação científica de forma lúdica e prazerosa.

Para a coleta de parte dos dados, foi utilizada a técnica etnográfica da observação participante que, segundo Spradley (1980, apud Correia, 2009) é uma estratégia que permite ao observador integrar-se às atividades, de forma que as pessoas deixam de ser objetos e passam a ser sujeitos da pesquisa. A observação participante deu-se em cinco encontros semanais. Os encontros iniciavam-se com uma aula de canto coral, seguida pelas atividades cênicas, conduzidas pelo diretor do grupo, Cauê Matos. Essas atividades incluíam: a) relaxamento induzido, cuja finalidade era voltar a atenção ao corpo, aos seus pontos de apoio no solo e à respiração, segundo o modo de pensar o corpo de Klauss Vianna ${ }^{1}$; b) exercícios para desenvolver a autoconfiança e a confiança no outro, estimular o toque e o equilíbrio; e c) exploração de recursos cênicos, ritmo, criatividade e uso da voz. Ao final, era solicitada a produção de encenações em grupo que deveriam ser avaliadas pelos presentes. Esta etapa visava, principalmente, estimular o trabalho cooperativo e a capacidade crítica.

\section{Entrevista com o diretor}

Foi gravada uma entrevista individual com o ator e diretor teatral Cauê Matos, cujo trabalho de pesquisa cênica é realizado com pessoas com idade acima de 60 anos. Essa entrevista teve o objetivo de avaliar como as atividades propostas nesse grupo de teatro - as quais evidenciam a expressão corporal e a conscientização sobre o próprio corpo - se relacionam com o aprendizado no seu sentido mais amplo, a partir da perspectiva de quem pensa e propõe tais atividades.

\section{Grupo focal}

Para investigar os aspectos relacionados ao corpo e ao aprendizado, a partir das vivências deste grupo, foi utilizada a técnica qualitativa grupo focal. Segundo Patton (1990), o grupo focal é uma técnica de coleta de dados altamente eficiente, que fornece alguns controles de qualidade sobre a coleta individual, visto que os participantes tendem a compensar um ao outro, eliminando, assim, opipróprio para desenvolver a expressão corporal na dança e no teatro, cujo objetivo era devolver o corpo às pessoas. 
niões falsas ou radicais. Além disso, consideramos razoavelmente fácil avaliar até que ponto existe uma opinião compartilhada e relativamente consistente entre os participantes. Esse tipo de abordagem foi escolhido por possuir, entre as principais vantagens, a rapidez de execução e a riqueza de dados, além de os participantes serem estimulados pelas respostas compartilhadas, o que os ajuda a lembrar de acontecimentos e a ultrapassar os limites das respostas de um único entrevistado. 0 grupo focal foi organizado a partir de temas que compreenderam aspectos relacionados: a) ao grupo de teatro, que incluiu conhecer as motivações pessoais para participação no Núcleo e as expectativas; b) ao corpo, quando os participantes foram convidados a discorrer sobre a percepção e o conhecimento sobre seu corpo e o do outro, bem como sobre a relação com o corpo na infância e na vida adulta, em diferentes contextos; e c) ao aprendizado, em que procuramos avaliar o potencial das atividades para o desenvolvimento de habilidades, modificações no autocuidado, saúde, bem-estar e qualidade de vida, ampliação da rede de suporte social, tanto nos colegas quanto em si mesmos.

\section{Análise dos dados}

Os dados do grupo focal foram analisados segundo a abordagem metodológica em pesquisa qualitativa denominada Discurso do Sujeito Coletivo (DSC), segundo (Lefèvre; Lefèvre, 2000). A entrevista com o diretor teve um caráter qualitativo exploratório, uma vez que pretendemos trabalhar com o universo de significados, motivos e objetivos, abordagem que favoreceu ao sujeito expressar suas opiniões e sentimentos vivenciados (Minayo, 1998).

\section{Resultados e discussão}

Embora, mais recentemente, a definição do processo de ensino-aprendizagem tenha sido ampliada, o que permite considerar que o aprender envolve desenvolvimento de competências e mudança de comportamento (Piaget, 1969), a complexidade desse processo dificilmente poderá ser compreendida, sem levar em conta pressupostos político-ideológicos relacionados à visão de homem, sociedade e saber.

A partir desses princípios, procuramos estudar a influência de uma atividade que evidencia o corpo, em diferentes aspectos da vida de adultos na maturidade, tais como, na ampliação da rede de suporte social; na relação com a família; no autocuidado; na apropriação de novos conhecimentos; e na percepção do próprio corpo e 
dos sentidos. Para essa finalidade, este trabalho foi organizado em duas vertentes: a primeira destinou-se a caracterizar a população de estudo, enquanto a segunda teve como objetivo obter os dados qualitativos referentes à relação do corpo com o aprendizado.

Inicialmente, foi aplicado um questionário com o objetivo de obter dados sociodemográficos dos participantes do grupo. Dos 15 participantes, 13 eram mulheres e dois eram homens, com idades que variavam entre 60 e 85 anos, e média de idade de 69 anos. As mulheres, em sua maioria, eram viúvas ou separadas, havendo apenas três casadas. A maioria dos participantes concluiu o Ensino Superior (65\%), distribuídos nos cursos de Economia, Licenciatura em Educação Infantil, Pedagogia, Cinema e Jornalismo. Os outros 35\% dividiram-se entre Ensino Médio e Primário. A maioria deles (66\%) utilizava-se de transporte público para deslocar-se até a Estação Ciência. Como quase não havia ausências nas aulas, inferimos que o grau de comprometimento com aquela atividade era grande. Isso foi percebido também nas respostas sobre a motivação para essa atividade, em que a maioria relatou gostar de teatro, de canto e de arte em geral. Quando perguntados sobre modificações observadas nos colegas desde o início do curso, a maioria relatou que os tímidos estavam mais extrovertidos; que todos estavam mais criativos, integrados ao grupo; haviam melhorado a postura, a voz; e estavam mais preocupados com a aparência. A participação nos encontros ao longo do semestre (agosto a novembro de 2010) foi revelando um crescente progresso na integração entre o grupo, na cooperação, na capacidade de analisar criticamente e na superação do estranhamento inicial.

Quanto à dinâmica dos encontros, os exercícios solicitados apresentaram um grau de dificuldade crescente e sempre tinham objetivos relacionados ao fazer teatral e ao aprendizado ampliado, apesar de, num primeiro momento, este propósito não ter ficado muito perceptível. Nos exercícios respiratórios, por exemplo, os participantes eram convidados a prestar atenção no caminho do ar, na caixa torácica, no diafragma, nos órgãos, enfim, a reconhecer as partes envolvidas naquele processo. Apesar das dificuldades, um dos objetivos era que as atividades desenvolvidas fossem prazerosas.

Um aspecto relevante na relação com os alunos, tanto por parte do diretor quanto da professora de coral cênico, era a atitude de não infantilizá-los. As dificuldades, as resistências e, até mesmo, as recusas de alguns em praticar alguma tarefa, resultavam numa atenção maior aos envolvidos, visando incentivar sua participação, sem uma atitude protecionista. É importante destacar esse aspecto, pois a infantilização 
de pessoas com idade avançada é um fato comum. Levy (2001) chamou a atenção para os preconceitos implícitos e formas de tratamento discriminativas que existem e operam sem o conhecimento ou o controle consciente das pessoas. Desse modo, consideramos frequentes as manifestações de ageismo, ou seja, de tratamento desigual em função da idade. No caso de pessoas mais velhas, isso se revela na forma paternalista de tratamento e na comunicação, principalmente por meio da utilização de termos no diminutivo. Segundo Couto (2009), estudos apontam que a linguagem simplificada, com pouca qualidade e vagarosa tem impacto significativamente negativo na autoestima, na identidade, na cidadania e na percepção de autoeficácia de pessoas idosas. Portanto, o tratamento não discriminativo dispensado ao grupo pode ser considerado um fator importante para o bom andamento dos trabalhos.

Além de conhecer as motivações dos participantes, outro objetivo desse trabalho foi estudar como essa atividade que evidencia o uso do corpo repercute em diferentes aspectos da vida da pessoa, nas relações familiares e nas possibilidades de aprendizado.

Foi verificado que as vivências nesse grupo constituem um momento de prazer e de autoconhecimento, de resgate da importância do próprio corpo e desse corpo na relação com o outro, conforme mostrado nos fragmentos a seguir, extraídos dos discursos dos entrevistados:

Despertei para isso de tocar o outro, conhecer o outro agora... é um aprendizado que sinto no corpo e não sei explicar. Eu estava procurando uma atividade prazerosa e aqui o trabalho com o corpo é diferenciado; a música e a dança servem para liberar quem tem preconceito com o corpo, para sentir o que o corpo pede. Parece que há uma fusão de mim com o teatro, um novo ser... a palavra é liberdade no corpo. (F.S.)

Outro fato importante foi identificar que as atividades realizadas permitiram evidenciar/revelar que a educação por eles recebida ou questões religiosas influenciaram o modo como se relacionavam com seus corpos, conforme mostrado nos trechos a seguir:

... na educação que eu tive, o valorizado era o intelecto e o espiritual, o corpo não era nada, você não tem que se dedicar ao seu corpo, né? (V.L.R.)

... eu investina parte intelectual, na psicológica e na cultural, e o corpo era um, o 
corpo vinhajunto, mas nenhum trabalho como corpo, nenhuma atenção. (E.K.)

... mas na educação que eu tive, baseada na tradição judaico-cristã o corpo não era nada, só a parte intelectual e a espiritual é que tinham valor, o corpo só vinha junto e era considerado pecaminoso. (E.K.)

Já que consideramos que a ideia central deste trabalho remete ao fato de que toda educação é a educação do corpo, tornou-se essencial conhecer aspectos da educação escolar formal dos participantes. Com relação a isso, podemos dizer que a educação recebida pela maioria dessas pessoas foi influenciada pela prática pedagógica iniciada nas décadas de 1930 e 1940, época em que se instaurou uma negação do que não era moderno ou industrial e se buscou a educação profissional em direção a uma sociedade racionalizada. Para tanto, o objetivo da educação era o de moldar as crianças e transformá-las em indivíduos que não provocassem confusão e desordem (Dewey, 1979 apud Danailof, 2005). Os depoimentos, além de revelarem aspectos das práticas pedagógicas dessa época, reforçaram a concepção do corpo como instrumento de acesso às capacidades mentais, dentro da lógica cartesiana, longe considerar que as pessoas aprendem quando conseguem atribuir significado ao conhecimento e se envolvem integralmente no processo (Maroni, 2008; Maturana, 1998).

De fato, ao considerarmos a aprendizagem como um processo contínuo e dinâmico em que se constrói e se desconstrói, e o desenvolvimento de competências como um recurso para aprender a conhecer, a conviver, a fazer e a ser, torna-se possivel entender que o aprender só ocorre quando se cria um espaço de convivência que permita experiências e reflexão (Maroni, 2008). Esse entendimento contribui ainda mais para a análise dos dados coletados a partir das experiências nesse grupo.

Por meio das declarações dos participantes, foi possível verificar que, além do fazer teatral, eles puderam exercitar a criatividade, lidar com imprevistos e superar obstáculos, o que evidencia a aquisição/desenvolvimento de habilidades, conforme destacado a seguir:

... quando decidi fazer o curso de teatro queria desenvolver algumas áreas de minha vida que ficaram obscurecidas e escondidas e só na maturidade descobri o quanto são importantes para minha felicidade; desenvolver meu lado 
feminino é uma delas e eu consegui... minha parte feminina se manifestou na leveza, na sonoridade das artes; foi um aprendizado... (M.S.)

... ter que elaborar as cenas a partir de uma ideia exigiu um trabalho de criação de todos... é mais difícil do que receber um texto pronto, mas foi muito bom perceber essa criatividade que estava dentro de mim... (M.L.)

... ter participado da construção da cena desde as primeiras ideias até levá-la ao palco deixou a impressão de um projeto, desde a criação, até a execução... o teatro é a própria vida... já nem sei mais se o teatro é a vida ou se a vida é composta de várias cenas de teatro... acho que se entrelaçam em unicidade... (V.L.R.)

Além disso, ao admitir que as pessoas aprendem quando são capazes de atribuir algum significado a um dado conhecimento, associando-o a outro (Maturana, 1998), e quando se envolvem de maneira integral do processo (Maroni, 2008), fica clara a relação entre esse tipo de atividade e a aprendizagem significativa. Assim, a aprendizagem pressupõe novos espaços/cenários para o processo ensino-aprendizagem e requer que consideremos o aprender muito mais do que um processo mental.

Outro objetivo desse trabalho foi entender como se dá o processo de aprendizagem do grupo a partir da perspectiva do diretor, Cauê Matos. Seu depoimento revelou que as vivências nesse grupo de teatro são capazes de influenciar vários aspectos da vida das pessoas, desde a melhora das dores, a superação de medos e, principalmente, a descoberta do próprio corpo.

Olha, meu foco não é realmente apontar para a saúde, para a cura, minha preocupação é mesmo cultural, é artística, teatro... porém, sabemos que trabalho de teatro leva a vários aspectos da vida, mesmo em relação ao corpo, em relação ao outro, então com isso ele acaba gerando possibilidades... ah, de cura, de terapia, que entra realmente em outras áreas e acaba com alguns problemas e tensões sendo resolvidos aqui... (Cauê Matos)

Na sua fala, percebemos que trabalhar com adultos na maturidade também abre possibilidades para acessar e enfrentar questões relacionadas às mudanças no corpo 
dos indivíduos que refletem no fazer teatral. Nesse sentido, ele reconhece a diferença entre o tempo de raciocínio e a execução do movimento, o que desperta para o fato de que o envelhecimento está associado a mudanças no sistema músculo-esquelético (Bertoncini; Wallbach, 2004) que nem sempre são acompanhadas por alterações cognitivas (Teixeira, 2006), embora as duas possam ocorrer simultaneamente. Ao reconhecer isso, Cauê procura adequar as atividades propostas ao grupo, conforme descrito em seu depoimento:

Notamos que o movimento necessitava de um tempo maior, mas o raciocínio não, dai esse conflito, né? Mente e corpo, mente e movimento, tal, não tem essa fluidez do movimento e daí como adaptar, né? Como fazer com que o teatro seguisse toda a sua estética sem comprometer essas limitações corporais... com o passar do tempo, você percebe um desenho fluindo nesse corpo, um movimento, ãh mais harmonioso... (Cauê Matos)

A relação entre corpo e aprendizagem também aparece constantemente em sua fala, quer seja relacionada ao movimento, à percepção de si mesmo ou a uma experiência transformadora.

... um movimento onde estão integrados pés, pernas, tronco, cabeça, braços, enfim, o corpo mesmo em movimento, né? num todo, com essa percepção mesmo, isso é aprendizado, né? Isso é o corpo se transformando, isso é o corpo se percebendo, e com isso, há novas possibilidades de entendimento, de movimento para esse corpo... com isso a gente percebe que, né?, relação do corpo com a aprendizagem, né? (Cauê Matos)

Considerando esses relatose as discussões aquitecidas, que foram indubitavelmente enriquecidas por sua análise diante dos dados disponíveis na literatura, é possível afirmar que atividades como esta, que evidenciam o corpo, colaboram para o aprendizado no seu sentido amplo. Esse aprendizado pode levar a mudanças no comportamento e ensejar novos hábitos e atitudes, favorecendo a expansão da rede de suporte social, como forma de suprir a redução natural dessa rede nessa fase da vida (Domingues, 2007), além do desenvolvimento e mobilização de habilidades e competências.

Embora existam inúmeras possibilidades de propor atividades para pessoas aci- 
ma de 60 anos, acreditamos que elas não devam ser pensadas somente para preencher seu tempo livre, mas também para desenvolver ou fazer aflorar habilidades como a criatividade, a capacidade de enfrentar e superar desafios. Ainda é desejável que estimulem mudanças no autocuidado, na qualidade de vida e na saúde. Entendemos que as atividades que alcançam melhores resultados são as que consideram as necessidades das pessoas, seus anseios, suas potencialidades e sua capacidade de aprendizagem. Isso é possível quando as pessoas são consideradas sujeitos ativos e quando há uma troca constante entre quem pensa a atividade e aqueles aos quais ela é destinada (Domingues; Rodrigues; Nunes, 2012).

As discussões suscitadas neste trabalho são, nesse sentido, enriquecedoras, tanto do ponto de vista dos temas gerontológicos que permearam o estudo, quanto no que tange às práticas pedagógicas. Tais discussões conduziram a reflexões sobre o corpo e sua relação com o aprendizado, bem como permitiram um (re)conhecimento do corpo como espaço de aprendizagem. Assim, a partir do diálogo entre educação, corpo e vivências desse grupo de teatro, pudemos pensar no papel dos educadores, na necessidade da educação permanente e também da criação de espaços para explorar a sensibilidade e o fazer artístico para todas as idades.

É preciso ressaltar ainda que, embora nesse trabalho tenha sido avaliada uma atividade elaborada para adultos na maturidade, a proposta de discutir o lugar do corpo no processo de ensino-aprendizagem não se limita a essa faixa etária e não se esgota aí. Ao contrário, requer que reconheçamos o óbvio, que os atores nesse processo são seres humanos integrais (corpo/mente/alma), que desenvolvem as potencialidades da vida por meio do aprendizado. Além disso, entendemos que o aprendizado deva se dar de forma prazerosa, divertida e amorosa, que são componentes indispensáveis para uma vida plena, saudável e com qualidade. 


\section{Referências bibliográficas}

BALTES, P. B.; Reese, H. W.; Lipsitt, L. P. Life-span developmental psychology. Annual Review of Psychology, New York, n. 31, p. 65-110, 1980.

BECKER, F. Ensino e construção do conhecimento; o processo de abstração reflexionante. Educação e Realidade, Porto Alegre, v. 18, n. 1, jan./jun. 1993.

BERTONCINI, A. J.; WALLBACH, M. C. S. Alterações músculo-esqueléticas na terceira idade. In: SALDANHA, A.; CALDAS, C. C. P. Saúde no idoso: a arte de cuidar. Rio de Janeiro: Interciência, 2004. p. 225-230.

BRASIL. Ministério da Saúde. Secretaria de Assistência à Saúde. Resolução n. 1, de 13 de junho de 1988. Normas de pesquisa em saúde: aspectos éticos da pesquisa em seres humanos. Programa nacional das doenças sexualmente transmissíveis e AIDS. Conselho Nacional da Saúde. Brasília, DF, 1998.

BRASIL. Secretaria de Educação Fundamental. Parâmetros curriculares nacionais: introdução aos parâmetros curriculares nacionais. Secretaria de Educação Fundamental. Brasília: MEC/SEE, 2001.

CAMARANO, A. A. Envelhecimento da população brasileira: uma contribuição demográfica. In: FREITAS, E.V; PY, L. et al. (Org.). Tratado de Geriatria e Gerontologia. Rio de Janeiro: Guanabara Koogan, 2006. p. 88-105.

CAMPOS, P. F. M. Relações corpo educação: um estudo sobre o lugar do corpo na Escola. Disponível em: http://unb.revistaintercambio.net.br/24h/pessoa/temp/ anexo/1/190/163.pdf 2006. Acesso em: 20 ago. 2010.

CORREIA, M.-C. B. A observação participante enquanto técnica de investigação. Revista Pensar Enfermagem, Lisboa, v. 13, n. 2, p. 30-36, 2009.

COUTO, M. C. P. P. Avaliação de discriminação contra idosos em contexto brasileiro Ageísmo. Revista Psicologia: Teoria e Pesquisa, v. 25, n. 4, 2009.

DANAILOF, K. Imagens da infância: a educação e o corpo em 1930 e 1940 no Brasil. Revista Brasileira de Ciências do Esporte, v. 26, n. 3, 2005.

DOMINGUES, M. A. R. C; DERNTL, A. M.; QUEIROZ Z. As redes sociais na senescência. In: FREITAS, E. V; PY, L. et al. (Org.). Tratado de Geriatria e Gerontologia, Rio de Janeiro: Guanabara Koogan, 2006. p. 771-780.

DOMINGUES, M. A. R. C; SILVA, G. R.; NUNES, V. A. Metodologias ativas: uma abordagem possível nas atividades de orientação gerontológica. 2012. (Bacharelado em Gerontologia) - Escola de Artes, Ciências e Humanidades, Universidade de São Paulo, São Paulo. 
DOWBOR, F. F. Quem educa marca o corpo do outro. 2. ed. São Paulo: Cortez, 2008. FOUCAULT, M. Vigiar e punir: nascimento da prisão. Petrópolis: Vozes, 3. ed. 1984, $264 p$.

FRAGA, A. B. O Evangelho do agito: uma forma de ativar o corpo e regular a vida. Projeto de tese (Doutorado) - Programa de Pós-Graduação em Educação, Faculdade de Educação da UFRGS, Porto Alegre, 2001.

GAYA, A. A reinvenção dos corpos: por uma pedagogia da complexidade. Revista Sociologias, Porto Alegre, ano 8, n. 15, jan./jun., p.250-272, 2006.

GOLDFARB, D. C. Corpo, tempo e envelhecimento. São Paulo: Casa do Psicólogo, 1998.

KALACHE, A.; KICKBUSCH, I. A global strategy for healthy ageing. World Health, p. 4-5, 1997.

LEFÈVRE, F.; LEFÈVRE, A. M. C. Discurso do sujeito coletivo: um novo enfoque em pesquisa qualitativa. Caxias do Sul: EDUCS, 2000.

LEVY, B. R. Eradication of ageism requires addressing the enemy within. The Gerontologist, v. 41, n. 5, p. 578-579, 2001.

MARONI, A. A. E por que não? - tecendo outras possibilidades interpretativas. Idéias e Letras, Aparecida, 2008.

MATURANA, H. Da Biologia e Psicologia. Porto Alegre: Artmed, 1998.

MATURANA, H.; VARELA F. A árvore do conhecimento. São Paulo: Palas Athena. 2001.

MERLEAU-PONTY, M. Fenomenologia da percepção. São Paulo: Martins Fontes, 1999.

MINAYO, M. C. S. O desafio do conhecimento: pesquisa qualitativa em saúde. 5. ed. São Paulo: Hucitec.1998.

NÓBREGA, T. P. Qual o lugar do corpo na educação? Notas sobre conhecimento, processos cognitivos e currículo. Educação e Sociedade, Campinas, v. 26, n.. 91, 2005.

PALMA, L. S.; CACHIONI M. Educação permanente: perspectiva para o trabalho educacional com o adulto maduro e com o idoso. In: FREITAS, E.V; PY, L. et al. (Org.). Tratado de Geriatria e Gerontologia. Rio de Janeiro: Guanabara Koogan, 2006. p. 1.101-1.118.

PATTON, M. Qualitative Evaluation and Research Methods. Newbury Park, C. A.: Sage Publications, 1990.

PELIZZARI, A. et al. Teoria da aprendizagem significativa segundo Ausubel. Revista PEC, Curitiba, v. 2, n. 1, 2002. 
PIAGET, J. Aprendizagem e conhecimento. Rio de Janeiro: Freitas Bastos, 1979.

PINTO, R. N. A educação do corpo e o processo civilizatório: a formação de "estátuas pensantes". Revista da Faculdade de Educação Física da Unicamp, v. 2, n. 4, 2004.

SANT'ANNA, D. História do conforto na cidade de São Paulo. Anos 90. Revista do Programa de Pós-Graduação em História da UFRGS, Porto Alegre, n.14, 2000.

SFEZ, L. A saúde perfeita: críticas de uma utopia. Lisboa: Instituto Piaget, 1995.

SOARES, C. L. Cultura de movimento. Revista do SESC/SP-Corpo, Prazere Movimento, n. 4, p. 15-23, 2002.

STRAZZACAPPA, M. A educação e a fábrica de corpos: a dança na escola. Cadernos CEDES, Campinas, Centro de Estudos Educação e Sociedade, n. 53, 2001.

TEIXEIRA, L. A. Declínio de desempenho motor no envelhecimento é específico à tarefa. Revista Brasileira Medicina Esporte, Niterói, v.12, n. 6, p. 351-354, nov. dez. 2006.

VICTOR, A. F.; LOPES, M. V. O.; ARAUJO, T. L. Teoria do déficit de autocuidado: análise da sua importância e aplicabilidade na prática de enfermagem. Revista da Escola Anna Nery, v. 14, n. 3, p. 611-616, jul./set. 2010. Impressa.

ZARANKIN, A. Paredes que domesticam: arqueologia da arquitetura escolar capitalista - o caso de Buenos Aires. Tese (Doutorado) - Centro de História da Arte e Arqueologia, IFCH-Unicamp-Fape, Campinas, 2002.

Submetido à publicação em 16 de agosto de 2012.

Aprovado em 13 de maio de 2013. 
